\title{
Quantitative Aspect of Leucophyllum frutescens Fraction before and after Encapsulation in Polymeric Nanoparticles
}

\author{
Claudia Janeth Martínez-Rivas, ${ }^{1,2}$ Rocío Álvarez-Román, ${ }^{3}$ Catalina Rivas-Morales, ${ }^{1}$ \\ Abdelhamid Elaissari, ${ }^{2}$ Hatem Fessi, ${ }^{2}$ and Sergio Arturo Galindo-Rodríguez ${ }^{1}$ \\ ${ }^{1}$ Facultad de Ciencias Biológicas, Laboratorio de Nanotecnología, Universidad Autónoma de Nuevo León, Av. Pedro de Alba s/n, \\ 66455 San Nicolás de los Garza, NL, Mexico \\ ${ }^{2}$ Univ Lyon, Université Claude Bernard Lyon 1, CNRS, LAGEP-UMR 5007, 69622 Lyon, France \\ ${ }^{3}$ Facultad de Medicina, Departamento de Química Analítica, Universidad Autónoma de Nuevo León, \\ Av. Fco. I. Madero y Dr. E. Aguirre Pequeño s/n, 64460 Monterrey, NL, Mexico
}

Correspondence should be addressed to Sergio Arturo Galindo-Rodríguez; sagrod@yahoo.com.mx

Received 18 May 2017; Revised 11 September 2017; Accepted 13 September 2017; Published 22 November 2017

Academic Editor: Anna V. Queralt

Copyright ( 2017 Claudia Janeth Martínez-Rivas et al. This is an open access article distributed under the Creative Commons Attribution License, which permits unrestricted use, distribution, and reproduction in any medium, provided the original work is properly cited.

\begin{abstract}
The interest on plants has been focalized due to their biological activities. Extracts or fractions from plants in biodegradable polymeric nanoparticles (NP) provide many advantages on application studies. The encapsulation of the extract or fraction in NP is determined for the establishment of the test dose. HPLC method is an alternative to calculate this parameter. An analytical method based on HPLC for quantification of a hexane fraction from $L$. frutescens was developed and validated according to ICH. Different concentrations of the hexane fraction from leaves (HFL) were prepared $(100-600 \mu \mathrm{g} / \mathrm{mL})$. Linearity, limit of detection, limit of quantification, and intra- and interday precision parameters were determined. HFL was encapsulated by nanoprecipitation technique and analyzed by HPLC for quantitative aspect. The method was linear and precise for the quantification of the HFL components. NP size was $190 \mathrm{~nm}$ with homogeneous size distribution. Through validation method, it was determined that the encapsulation of components (1), (2), (3), and (4) was 44,74, 86, and 97\%, respectively. A simple, repeatable, and reproducible methodology was developed for the propose of quantifying the components of a vegetable material loaded in NP, using as a model the hexane fraction of $L$. frutescens leaves.
\end{abstract}

\section{Introduction}

Since prehistoric times, medicinal plants have been used as treatments for numerous human diseases $[1,2]$. Recently, research articles have proved biological activities of some plant extracts as antioxidant $[3,4]$, anti-inflammatory [4], antimicrobial [5, 6], and anticancer [7] activity. Organic solvents are used in the extraction process to obtain the active plant material [8] and as carrier in the assays for extract application. However, for in vivo administration, an organic solvent would result in toxicity for the organism [9].

Different carriers as nanocomposite films [10], microparticles [11], and nanoparticles [12, 13] have been a good alternative as drug delivery systems. Particularly, polymeric nanoparticles (NP) are promising as carriers which present sustained release and protection to the active [14] and targeting to specific organs $[15,16]$. During NP preparation the organic solvent has to be eliminated. Researches in natural products encapsulation have demonstrated beneficial effects. Arrabidaea chica is a plant with healing properties employed in folk medicine for wound healing, inflammation, and gastrointestinal colic. Servat-Medina et al. studied the antiulcerogenic activity. A. chica hydroalcoholic extract was incorporated in chitosan-sodium tripolyphosphate NP. An in vitro study in human skin fibroblasts showed biocompatibility. In vivo study proved that $A$. chica hydroalcoholic extractloaded NP enhances its antiulcerogenic activity [17]. Similar behaviors were obtained by Kwon et al. They investigated 
different activities of the aqueous extract of Centella asiatica loaded gelatin NP. Encapsulated aqueous extract presented lower toxicity in human skin fibroblasts. Extract-loaded NP displayed a stronger inhibition of enzymatic activity that affects dermal tissues, flux through mouse skin, and retention. These results showed the potential use of aqueous extract of C. asiatica loaded NP in cosmetic industry [18].

As well as drug encapsulation, extract encapsulation involves the NP characterization, loading ( $\% L$ ), and encapsulation efficiency (\% EE). Besides, being two of the main parameters determined for NP characterization [19], in in vitro and in vivo studies, it is important to establish the test dose in treatments. UV-Vis spectrophotometry has been used for extract-loaded NP quantification $[17,20]$. However, quantification of low concentrations is limited for its poor sensitivity. High performance liquid chromatography (HPLC) is a method used to separate the marker compounds in extracts or fractions for their subsequent quantification [21, 22]. Sangthong and Weerapreeyakul identified two compounds (sulforaphene and sulforaphane) in Raphanus sativus L. var. caudatus Alef extracts. Quantification of both molecules was carried out through a validated HPLC method [23]. Thus, development and validation of a method based on separation of known molecules in the plant and their quantification in NP are promising.

However, there are plants less studied as Leucophyllum frutescens, Scrophulariaceae family, is commonly known as "cenizo." This plant is the bush par excellence of Nuevo León, while, in Texas, it is called the "bush barometer" due to its surprising flowering depending on the humidity in the environment and precipitation rain [24]. L. frutescens has received attention for its anti-M. tuberculosis activity. Methanol extract from leaves has presented biological activity against multidrug-resistant (MDR) M. tuberculosis strains [25] and two new active compounds from hexane fraction of $L$. frutescens against these bacteria have been described $[26,27]$. We posed hexane fraction loaded NP as promising agent against multidrug-resistant (MDR) strain and NP administration in systems involves knowing the fraction encapsulation. In this context, the aim of this study was to propose the development and validation of an analytical method by HPLC using internal marker compounds for the quantification of the hexane fraction from $L$. frutescens leaves (HFL) loaded in NP.

\section{Materials and Methods}

2.1. Plant Material and Reagents. L. frutescens was collected in Monterrey; N. L. Methanol (Tedia, USA), formic acid (purity: 90\%, Millipore, USA), and acetonitrile (J.T. Baker, USA) were HPLC-grade. Purified water was from a Milli$Q$ water-purification system (Millipore, USA). Poly-L-lactide acid (PLA) (PURASORB, PURAC biochem BV, Gorinchem, $\mathrm{HOL}$ ) as the NP-formed polymer and polyvinyl alcohol (PVAL, Clariant, Mexico) as stabilizer. Other solvents used were of analytical grade.

2.2. Chromatographic Analysis. High performance liquid chromatography assay was performed with a photodiode array detector (HPLC-DAD) (Varian 9065, 9012, ProStar 410, USA). A Synergi ${ }^{\mathrm{TM}} 4 \mu \mathrm{m}$ Fusion-RP $80 \AA(150 \mathrm{~mm} \times 2.0 \mathrm{~mm}$ $\times 4 \mu \mathrm{m})$ column was used with a flow rate of $0.2 \mathrm{~mL} / \mathrm{min}$ and maintained at $30^{\circ} \mathrm{C}$. Two methods were carried out; for method 1 , the mobile phase was formic acid $0.1 \% \mathrm{v} / \mathrm{v}(\mathrm{A})$ and methanol (B). Gradient conditions were as follows: a gradual change from $45: 55$ (A:B) to 100 (B) was completed during 0-20 min, and then 100 (B) was maintained for 20-35 min. For method 2, the mobile phase was an isocratic elution with $45: 55$ (A : B) during $40 \mathrm{~min}$. Detection wavelength was set at $210,215,220$, and $229 \mathrm{~nm}$. The peaks at $210 \mathrm{~nm}$ were detected, based on peak areas at the maximum wavelength.

2.3. Preparation of Calibration Curve. The leaves of $L$. frutescens (50 g) were dried at room temperature, pulverized, and extracted with methanol $(350 \mathrm{~mL})$ with sonication (Ultrasonic Cleaners, VWR Symphony, USA). The methanol extract was evaporated under reduced pressure (Laborota 4003 control, Heidolph). Liquid-liquid partition was carried out with hexane. The hexane fraction from leaves (HFL) was evaporated under reduced pressure. For the preparation of stock solution, the total semisolid HFL was weighed and dissolved in methanol. Then, this solution was filtered through a $0.45 \mu \mathrm{m}$ membrane filter (Millipore, USA). The working solutions were prepared in a concentration range from 100 to $600 \mu \mathrm{g} / \mathrm{mL}$ in triplicate and filtered for their HPLC-DAD analysis to obtain the calibration curve.

2.4. Method Validation. The method was validated for linearity, limit of detection (LOD), limit of quantification (LOQ), and intra- and interday precision according to International Conference on Harmonisation [28]. For the establishment of linearity, five levels of concentration were prepared in a range from 100 to $600 \mu \mathrm{g} / \mathrm{mL}$ in triplicate, while the LOD and LOQ were calculated from the calibration curve according to

$$
\begin{aligned}
& \mathrm{LOD}=\frac{3.3 \sigma}{S}, \\
& \mathrm{LOQ}=\frac{10 \sigma}{S},
\end{aligned}
$$

where $\sigma$ is the standard deviation of the response and $S$ is the slope of the calibration curve. The residual standard deviation of a line regression or the standard deviation of $y$-intercepts of lines regression may be used as the standard deviation. Finally, the intra- and interday precision were determined analyzing three concentrations with six replicates each one, during a single day and on three different days, respectively.

Once the chromatographic method was established and validated, NP were prepared according to the procedure of nanoprecipitation technique developed by Fessi et al. [29]. Briefly, the organic phase was prepared by dissolving $30 \mathrm{mg}$ of PLA and $3 \mathrm{mg}$ of hexane fraction in $3 \mathrm{~mL}$ of an organic solvent mixture (acetone: methanol). The organic solution was added to $10 \mathrm{~mL}$ of aqueous phase containing PVAL $(1 \%, w / w)$ and stirred magnetically. The organic solvent was evaporated at reduced pressure. NP characterization was carried out determining size and size distribution index (PDI) by dynamic light scattering (DLS) (Zetasizer Nano 
ZS90, Malvern Instruments, UK). The morphology of the NP was observed using a FEI Quanta 250 FEG Microscope at the "Centre Technologique des Microstructures" (CT $\mu$, Claude Bernard University Lyon 1, France). For the preparation of SEM samples, a drop of diluted aqueous suspension was deposited on a flat metallic holder and dried at room temperature. The sample was finally coated under vacuum by cathodic sputtering with platinum. The samples were observed by SEM under an accelerating voltage of $10 \mathrm{kV}$. For encapsulation loading $(\% L)$ and encapsulation efficiency (\% EE), NP dispersions were centrifuged at 25,000 rpm (Allegra 64R, Beckman Coulter, USA) and obtained pellets were lyophilized (Freeze Dry System, LABCONCO, USA). Lyophilized NP were dissolved in acetonitrile-methanol. Solutions were analyzed by HPLC to quantify the encapsulated peaks by the parameters: $\% L$ and $\% \mathrm{EE}$, according to the following:

$$
\% L=\frac{\text { Amount of peak/component in NP }}{\text { Mass of lyophilized NP }} \times 100
$$

$$
\% \mathrm{EE}=\frac{\text { Amount of peak/component in NP }}{\text { Total amount of peak/component }} \times 100 \text {. }
$$

\section{Results and Discussion}

3.1. Development of the Chromatographic Method by HPLC. In medicinal plants, there are hundreds of unknown components. Variability within the same herbal materials [21] depends on the collection station and the origin of the plant, among other factors [30]. For this reason, the determination of the chromatographic profile is a useful tool for the quality control of plant extract samples [31-34]. HPLC analysis is carried out for knowledge of the chromatographic profile of the vegetal samples [21].

L. frutescens is a plant less studied that has demonstrated to be promising for its use against tuberculosis. In this way, to obtain the chromatographic profile using the hexane fraction of $L$. frutescens leaves increases the knowledge about the plant. Method 1 was developed to obtain the chromatographic profile HFL. Figure 1(a) shows 16 peaks at a concentration of $400 \mu \mathrm{g} / \mathrm{mL}$ of the fraction and the main peaks are (1)-(4). Method 2 was developed to separate these four main peaks and validated for quantification of peaks (Figure 1(b)). In both chromatograms each peak corresponds to one component of the fraction [35]. Method 2 was validated to quantify the components in the hexane fraction loaded NP.

To increase the knowledge about the plant, a searching for some compounds found in L. frutescens family called Scrophulariaceae was performed; three compounds, quercetin [36], luteolin, and apigenin [37], were selected and analyzed by HPLC method 2. The HPLC analysis was carried out and retention time of each one was obtained (Figure 1(c)). Compared with the retention time of the four components in HFL observed by the same method, peak-component (1) (15.48 $\mathrm{min}$ ) would be apigenin $(16.07 \mathrm{~min})$. It is necessary to analyze HFL by spectroscopic methods to assign the presence of this compound.
3.2. Validation of Analytical Procedure: Linearity, Limit of Detection, Limit of Quantification, and Intra- and Interday Precision. The developed HPLC-DAD method has demonstrated to be simple, sensitive, specific, and adequate for the simultaneous quantification [38]. The validation was performed to know the linearity and the precision of the chromatographic method (method 2) for the quantification of the peaks-components of HFL loaded NP. For the establishment of linearity, a minimum of 5 concentrations is recommended by the $\mathrm{ICH}$ [28]. A calibration curve of the semisolid HFL in acetonitrile-methanol at a concentration range from 100 to $600 \mu \mathrm{g} / \mathrm{mL}$ was prepared. The area under the curve in each concentration level of each peakcomponent was analyzed to obtain Figure 2. Consequently, regression equation, correlation coefficient, LOD, and LOQ of each peak-component were established (Table 1). The acceptance criterion for linearity is given by the correlation coefficient [28, 39]. For quantification of content or active ingredient, the coefficient must be greater than or equal to 0.99 [39].

As shown in Table 2, correlation coefficients for calibration curve of each peak-component are greater than 0.99 . LOD and LOQ for peaks-components (1), (2), (3), and (4) were determined, being 53.73 and 162.83, 60.00 and 181.80, 44.27 and 134.15 , and 101.47 and $307.49 \mu \mathrm{g} / \mathrm{mL}$, respectively. Da Silva et al. quantified simultaneously quercetin and rosmarinic acid in sage and savoury (Salvia sp. and Satureja montana, resp.) from a calibration curve with standard compounds. LOD and LOQ were found to be 20 and $80 \mu \mathrm{g} / \mathrm{mL}$ for rosmarinic acid, respectively. For quercetin, they were 30 and $90 \mu \mathrm{g} / \mathrm{mL}$, respectively [40]. In our study, higher values have been determined due to LOD and LOQ values and have been established with respect to the concentration of total HFL.

Intra- and interday precision of the chromatographic method were determined analyzing three concentrations with six replicates each one, during a single day and on three different days; in order to obtain their RSD, results of these parameters are shown in Table 1. Intra- and interday variations were around $9.34 \%$ and $10.51 \%$, respectively. Ying et al. used Angelica sinensis, a famous traditional Chinese medicinal herb. Many kinds of compounds have been isolated and identified from the plant. They validated a method for the simultaneous quantification of six active compounds present in A. sinensis (ferulic acid, senkyunolide $\mathrm{I}$, senkyunolide $\mathrm{H}$, coniferyl ferulate, $\mathrm{Z} / \mathrm{E}$-ligustilide, and Z/E-butylidenephthalide) from a mixture of standards. The precision of the quantification method had an intraday RSD below $2.43 \%$ and interday below $5.00 \%$ [41].

\subsection{Preparation and Characterization of the Hexane Fraction} from L. frutescens Incorporated in Polymeric Nanoparticles. Nanoprecipitation technique described by Fessi et al. was used for NP preparation. The size of obtained NP formulation was $189.70 \pm 3.80 \mathrm{~nm}$ with homogeneous distribution (Figure 3). SEM was used to visualize the morphology. Particles were evaluated on the basis of shape and presence of interparticulate bridging. Under SEM observation, the submicron particles produced had spherical shapes and showed a homogenous particle size distribution (Figure 4). 


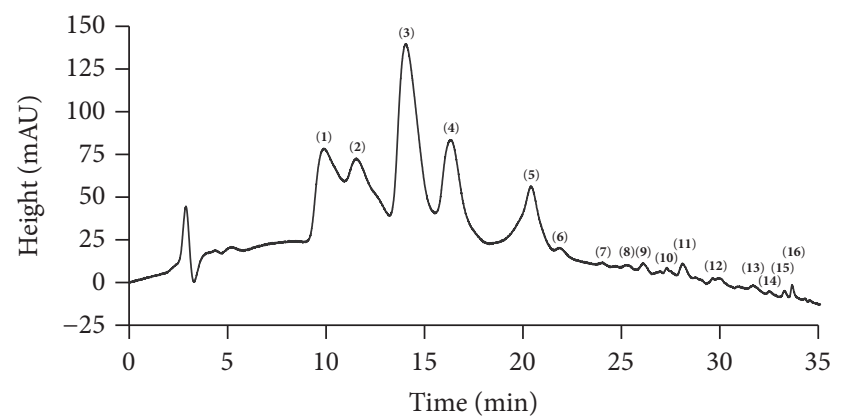

(a)

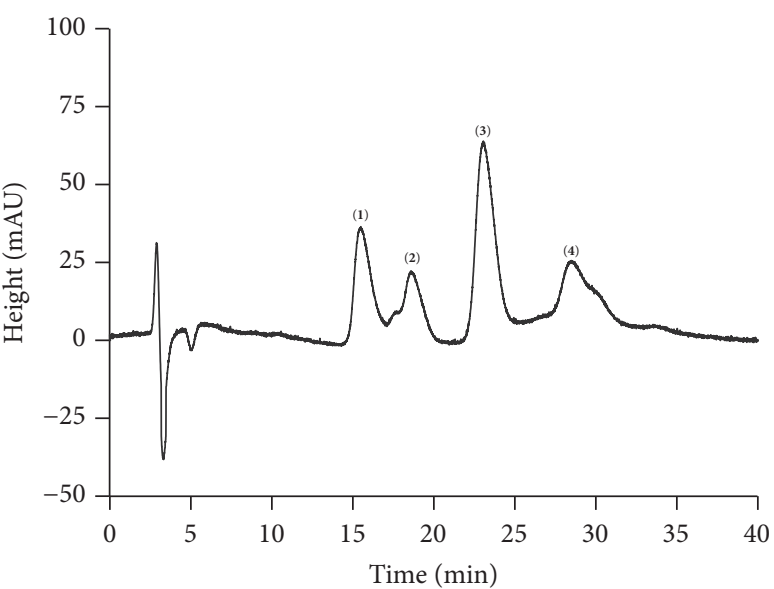

(b)

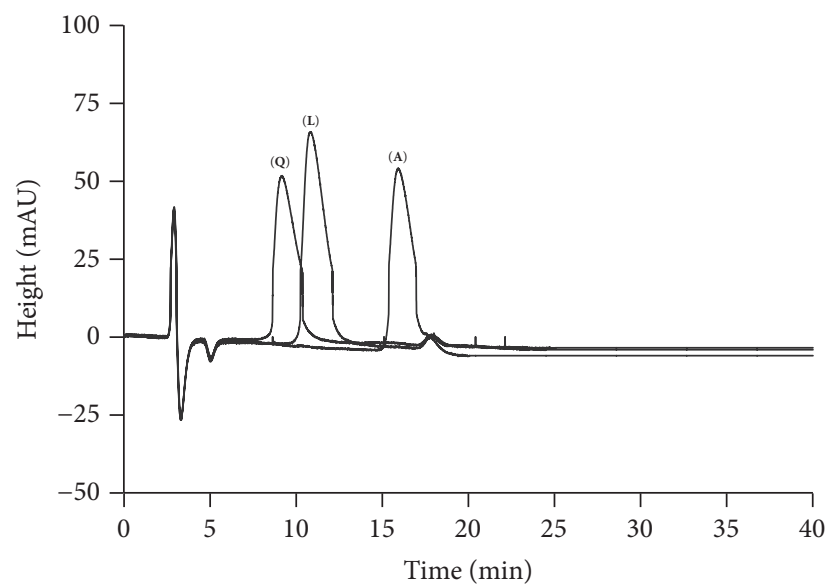

(c)

FIGURE 1: Chromatographic profile of hexane fraction from $L$. frutescens leaves ( $400 \mu \mathrm{g} / \mathrm{mL}$ ) by HPLC (a) method 1: chromatogram shows 16 peaks-components with a retention time of $9.88,11.50,14.04,16.34,20.40,21.88,24.04,25.30,26.11,27.32,28.11,29.94,31.62,32.52,33.27$, and 33.66 min. (b) Method 2: chromatogram shows 4 peaks-components with a retention time of 15.48, 18.61, 23.05, and 28.49 min. (c) Quercetin (Q), luteolin (L), and apigenin (A) with retention time of 9.31, 10.97, and $16.07 \mathrm{~min}$, respectively, analyzed by method 2.

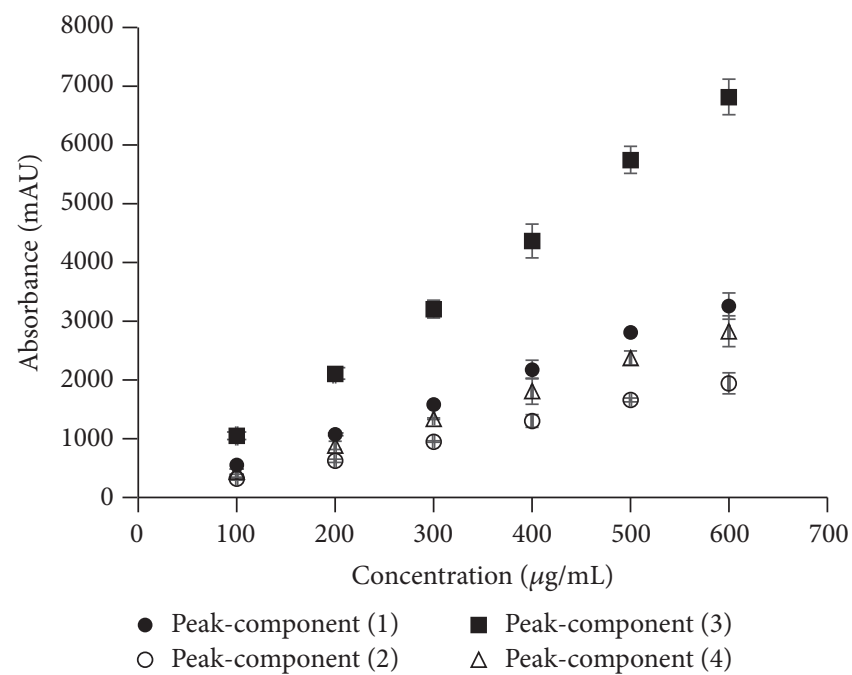

FIgURE 2: Calibration curve for the four peaks-components present in the hexane fraction from L. frutescens leaves (Mean \pm SD, $n=3)$. 
TABLE 1: Validation parameters for the four peaks-components in hexane fraction from Leucophyllum frutescens leaves.

\begin{tabular}{|c|c|c|c|c|c|c|}
\hline Peak-component & $\begin{array}{c}\text { Regression } \\
\text { equation }\end{array}$ & $\begin{array}{c}\text { Correlation } \\
\text { coefficient } \\
(r)\end{array}$ & $\begin{array}{c}\text { LOD } \\
(\mu \mathrm{g} / \mathrm{mL})\end{array}$ & $\begin{array}{c}\mathrm{LOQ} \\
(\mu \mathrm{g} / \mathrm{mL})\end{array}$ & $\begin{array}{l}\text { Intraday } \\
\text { precision } \\
(\mathrm{RSD}, \%)\end{array}$ & $\begin{array}{l}\text { Interday } \\
\text { precision } \\
(\mathrm{RSD}, \%)\end{array}$ \\
\hline (1) & $y=5.5199 x-22.689$ & 0.99 & 53.73 & 162.83 & 4.10 & 6.08 \\
\hline (2) & $y=3.3057 x-23.667$ & 0.99 & 60.00 & 181.81 & 6.93 & 6.41 \\
\hline (3) & $y=11.692 x-209.84$ & 0.99 & 44.27 & 134.15 & 7.30 & 7.28 \\
\hline (4) & $y=4.8221 x-74.844$ & 0.99 & 101.47 & 307.49 & 9.34 & 10.51 \\
\hline
\end{tabular}

TABLE 2: Characterization of hexane fraction from L. frutescens leaves loaded biodegradable polymeric nanoparticles.

\begin{tabular}{|c|c|c|c|c|}
\hline \multirow{2}{*}{ Size (nm) } & \multirow{2}{*}{ PDI } & \multicolumn{3}{|c|}{ Quantification } \\
\hline & & Peak-component & $\% L$ & $\% \mathrm{EE}$ \\
\hline \multirow{4}{*}{$189.7 \pm 3.81$} & \multirow{4}{*}{$0.138 \pm 0.026$} & (1) & $4.01 \pm 0.48$ & $44.23 \pm 5.35$ \\
\hline & & (2) & $6.74 \pm 0.64$ & $74.34 \pm 6.97$ \\
\hline & & (3) & $7.87 \pm 0.78$ & $86.78 \pm 8.62$ \\
\hline & & $(4)$ & $8.81 \pm 0.34$ & $97.03 \pm 3.44$ \\
\hline
\end{tabular}

Mean $\pm \operatorname{SD}(n=3)$.

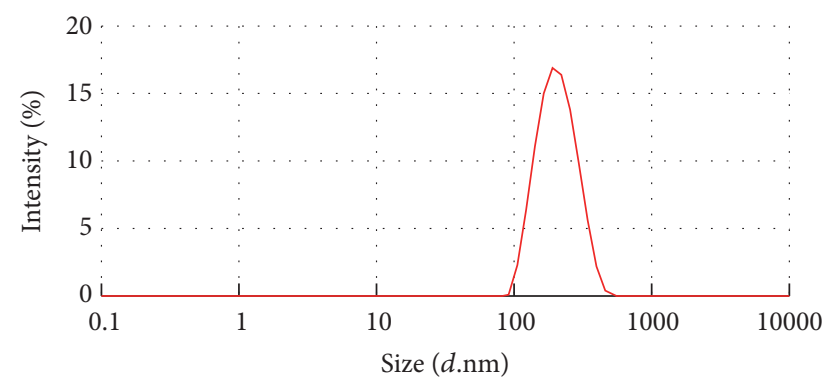

FIGURE 3: Size distribution of HFL loaded NP measured by the DLS technique.

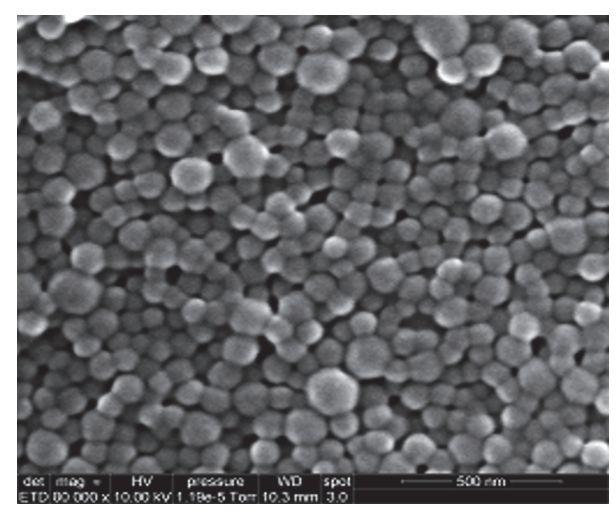

FIGURE 4: SEM image of PLA nanoparticles prepared by the nanoprecipitation method (scale bar represents $500 \mathrm{~nm}$ ).

After that, lyophilized pellet of HFL loaded NP was dissolved in acetonitrile/methanol and solutions were analyzed by HPLC. The area under the curve obtained from each peakcomponent was replaced in its regression equation (Table 1), in order to obtain the concentration of four peak-components in NP. Consequently, equations (2) were used to determine
$\% L$ and $\%$ EE of each peak-component (Table 2). The encapsulation of the peaks-components in NP was 44, 74, 86, and $97 \%$ of peaks (1), (2), (3), and (4), respectively. Based on the separation of peaks by HPLC method, first peak is the less hydrophobic, in NP representing the lowest encapsulation. The most hydrophobic peak in NP represents the highest encapsulation. Studies have reported that nanoprecipitation method is highly favorable in the encapsulation of the hydrophobic compounds [42]. Dalpiaz et al. mentioned that, compared PLGA with PLA, PLA has a lower hydrophilicity [43]. In this study, the method of NP preparation as well as the NP-formed polymer permits higher encapsulation percentage of the hydrophobic peaks-components.

\section{Conclusions}

L. frutescens is a plant with potential use. Chromatographic profile is part of characterization of extracts or fractions obtained from plants. In this study, we developed a chromatographic method to obtain the chromatographic profile of hexane fraction of $L$. frutescens leaves. The chromatographic method was validated based on the presence of the peakscomponents in HFL, in order to quantify them in NP. HFL loaded NP suspension around $190 \mathrm{~nm}$ was obtained. NP-formed polymer and nanoprecipitation method were favorable to encapsulate the hydrophobic components of $L$. frutescens extract.

\section{Conflicts of Interest}

The authors declare that there are no conflicts of interest regarding the publication of this article.

\section{Acknowledgments}

The authors gratefully acknowledge the financial supports by PRODEP-SEP Networks, Mexico, DSA/103.5/15/14156, 
AIRD, France (JEAI-2011, NANOBIOSA), PN-CONACYT, Mexico, 2014-248560, and PAICYT-UANL, Mexico. Claudia Janeth Martínez-Rivas is thankful for CONACyT scholarship, Mexico, no. 280112.

\section{References}

[1] D. J. Bharali, I. A. Siddiqui, V. M. Adhami et al., "Nanoparticle delivery of natural products in the prevention and treatment of cancers: Current status and future prospects," Cancers, vol. 3, no. 4, pp. 4024-4045, 2011.

[2] E. A. Palombo, "Traditional medicinal plant extracts and natural products with activity against oral bacteria: potential application in the prevention and treatment of oral diseases," Evidence-Based Complementary and Alternative Medicine, vol. 2011, Article ID 680354, 15 pages, 2011.

[3] V. Kraujaliene, A. Pukalskas, P. Kraujalis, and P. R. Venskutonis, "Biorefining of Bergenia crassifolia L. roots and leaves by high pressure extraction methods and evaluation of antioxidant properties and main phytochemicals in extracts and plant material," Industrial Crops and Products, vol. 89, pp. 390-398, 2016.

[4] J. Malik, J. Tauchen, P. Landa et al., "In vitro antiinflammatory and antioxidant potential of root extracts from Ranunculaceae species," South African Journal of Botany, vol. 109, pp. 128-137, 2017.

[5] S. Akroum, "Antifungal activity of acetone extracts from Punica granatum L., Quercus suber L. and Vicia faba L," Journal de Mycologie Médicale, vol. 27, no. 1, pp. 83-89, 2017.

[6] A. A. Mostafa, A. A. Al-Askar, K. S. Almaary, T. M. Dawoud, E. N. Sholkamy, and M. M. Bakri, "Antimicrobial activity of some plant extracts against bacterial strains causing food poisoning diseases," Saudi Journal of Biological Sciences, 2016.

[7] R. B. Villacorta, K. F. J. Roque, G. A. Tapang, and S. D. Jacinto, "Plant extracts as natural photosensitizers in photodynamic therapy: in vitro activity against human mammary adenocarcinoma MCF-7 cells," Asian Pacific Journal of Tropical Biomedicine, vol. 7, no. 4, pp. 358-366, 2017.

[8] M. N. Alam, N. J. Bristi, and M. Rafiquzzaman, "Review on in vivo and in vitro methods evaluation of antioxidant activity," Saudi Pharmaceutical Journal, vol. 21, no. 2, pp. 143-152, 2013.

[9] J. Maes, L. Verlooy, O. E. Buenafe, P. A. M. de Witte, C. V. Esguerra, and A. D. Crawford, "Evaluation of 14 Organic Solvents and Carriers for Screening Applications in Zebrafish Embryos and Larvae," PLoS ONE, vol. 7, no. 10, Article ID e43850, 2012.

[10] L. Floroian, C. Ristoscu, G. Candiani et al., "Antimicrobial thin films based on ayurvedic plants extracts embedded in a bioactive glass matrix," Applied Surface Science, vol. 417, pp. 224233, 2016.

[11] T. Klein, R. Longhini, M. L. Bruschi, and J. C. P. De Mello, "Microparticles containing Guaraná extract obtained by spraydrying technique: Development and characterization," Revista Brasileira de Farmacognosia, vol. 25, no. 3, pp. 292-300, 2015.

[12] T. G. do Nascimento, P. F. da Silva, L. F. Azevedo et al., "Polymeric Nanoparticles of Brazilian red propolis extract: preparation, characterization, antioxidant and leishmanicidal activity," Nanoscale Research Letters, vol. 11, no. 1, article 301, 2016.

[13] Y. Zhou, C. Guo, H. Chen, Y. Zhang, X. Peng, and P. Zhu, "Determination of sinomenine in cubosome nanoparticles by
HPLC technique," Journal of Analytical Methods in Chemistry, vol. 2015, Article ID 931687, 2015.

[14] J.-W. Yoo, N. Giri, and C. H. Lee, "pH-sensitive Eudragit nanoparticles for mucosal drug delivery," International Journal of Pharmaceutics, vol. 403, no. 1-2, pp. 262-267, 2011.

[15] O. O. Maksimenko, L. V. Vanchugova, E. V. Shipulo et al., "Effects of technical parameters on the physicochemical properties of rifampicin-containing polylactide nanoparticles," Pharmaceutical Chemistry Journal, vol. 44, no. 3, pp. 151-156, 2010.

[16] R. Pandey and G. K. Khuller, "Nanotechnology based drug delivery system(s) for the management of tuberculosis," Indian Journal of Experimental Biology (IJEB), vol. 44, no. 5, pp. 357366, 2006.

[17] L. Servat-Medina, A. González-Gómez, F. Reyes-Ortega et al., "Chitosan-tripolyphosphate nanoparticles as Arrabidaea chica standardized extract carrier: Synthesis, characterization, biocompatibility, and antiulcerogenic activity," International Journal of Nanomedicine, vol. 10, pp. 3897-3909, 2015.

[18] M. C. Kwon, W. Y. Choi, Y. C. Seo et al., "Enhancement of the Skin-Protective Activities of Centella asiatica L. Urban by a Nano-encapsulation Process," Journal of Biotechnology, vol. 157, no. 1, pp. 100-106, 2012.

[19] A. C. de Mattos, N. M. Khalil, and R. M. Mainardes, "Development and validation of an HPLC method for the determination of fluorouracil in polymeric nanoparticles," Brazilian Journal of Pharmaceutical Sciences, vol. 49, no. 1, pp. 117-126, 2013.

[20] R. Renuka, P. Sandhya, B. N. Vedha Hari, and D. Ramya Devi, "Design of polymeric nanoparticles of Emblica officinalis extracts and study of in vitro therapeutic effects," Current Trends in Biotechnology and Pharmacy, vol. 7, no. 3, pp. 716-724, 2013.

[21] Y.-Z. Liang, P. Xie, and K. Chan, "Quality control of herbal medicines," Journal of Chromatography B, vol. 812, no. 1-2, pp. 53-70, 2004.

[22] B. Medeiros-Neves, F. M. Corrêa De Barros, G. L. Von Poser, and H. F. Teixeira, "Quantification of coumarins in aqueous extract of Pterocaulon balansae (Asteraceae) and characterization of a new compound," Molecules, vol. 20, no. 10, pp. 1808318094, 2015.

[23] S. Sangthong and N. Weerapreeyakul, "Simultaneous quantification of sulforaphene and sulforaphane by reverse phase HPLC and their content in Raphanus sativus L. var. caudatus Alef extracts," Food Chemistry, vol. 201, pp. 139-144, 2016.

[24] O. Z. Zaragoza, "Guía de árboles y otras plantas nativas en la zona metropolitana de monterrey," Fondo Editorial de NL, 2009.

[25] G. M. Molina-Salinas, A. Pérez-López, P. Becerril-Montes, R. Salazar-Aranda, S. Said-Fernández, and N. W. D. Torres, "Evaluation of the flora of Northern Mexico for in vitro antimicrobial and antituberculosis activity," Journal of Ethnopharmacology, vol. 109, no. 3, pp. 435-441, 2007.

[26] B. Alanís-Garza, R. Salazar-Aranda, R. Ramírez-Durón, E. Garza-González, and N. W. De Torres, "A new antimycobacterial furanolignan from Leucophyllum frutescens," Natural Product Communications (NPC), vol. 7, no. 5, pp. 597-598, 2012.

[27] G. M. Molina-Salinas, V. M. Rivas-Galindo, S. Said-Fernández et al., "Stereochemical analysis of leubethanol, an anti-TB-active serrulatane, from Leucophyllum frutescens," Journal of Natural Products, vol. 74, no. 9, pp. 1842-1850, 2011.

[28] International Coference on Harmonisation (ICH), Validation of Analytical Procedures: Text and Methodology, [Online]. Available: https://www.ich.org/fileadmin/Public_Web_Site/ ICH_Products/Guidelines/Quality/Q2_R1/Step4/Q2_R1__Guideline.pdf, 2005. 
[29] H. Fessi, F. Piusieux, J. P. Devissaguet, N. Ammoury, and S. Benita, "Nanocapsule formation by interfacial polymer deposition following solvent displacement," International Journal of Pharmaceutics, vol. 55, no. 1, pp. R1-R4, 1989.

[30] N. Nguyen Hoai, B. Dejaegher, C. Tistaert et al., "Development of HPLC fingerprints for Mallotus species extracts and evaluation of the peaks responsible for their antioxidant activity," Journal of Pharmaceutical and Biomedical Analysis, vol. 50, no. 5, pp. 753-763, 2009.

[31] X. He, J. Li, W. Zhao, R. Liu, L. Zhang, and X. Kong, "Chemical fingerprint analysis for quality control and identification of Ziyang green tea by HPLC," Food Chemistry, vol. 171, pp. 405411, 2015.

[32] Y. Xie, Z.-H. Jiang, H. Zhou et al., "Combinative method using HPLC quantitative and qualitative analyses for quality consistency assessment of a herbal medicinal preparation," Journal of Pharmaceutical and Biomedical Analysis, vol. 43, no. 1, pp. 204-212, 2007.

[33] S.-O. Yang, S. W. Lee, Y. O. Kim et al., "HPLC-based metabolic profiling and quality control of leaves of different Panax species," Journal of Ginseng Research, vol. 37, no. 2, pp. 248-253, 2013.

[34] J.-H. Kim, C.-S. Seo, S.-S. Kim, and H.-K. Shin, "Quality assessment of Ojeok-san, a traditional herbal formula, using highperformance liquid chromatography combined with chemometric analysis," Journal of Analytical Methods in Chemistry, vol. 2015, Article ID 607252, 11 pages, 2015.

[35] J. Zaiyou, W. Wenquan, X. Guifang, M. Li, and H. Junling, "Comprehensive quality evaluation of Chishao by HPLC," Nutrición Hospitalaria, vol. 28, no. 5, pp. 1681-1687, 2013.

[36] A. Grigore, S. Colceru-Mihul, S. Litescu, M. Panteli, and I. Rasit, "Correlation between polyphenol content and antiinflammatory activity of Verbascum phlomoides (mullein)," Pharmaceutical Biology, vol. 51, no. 7, pp. 925-929, 2013.

[37] M. Nikolova, R. Gevrenova, and S. Ivancheva, "External flavonoid aglycones from Veronica chamaedrys L. (Scrophulariaceae)," Acta Pharmaceutica, vol. 53, no. 2, pp. 145-149, 2003.

[38] F.-C. Chen, L.-H. Wang, J. Guo, X.-Y. Shi, and B.-X. Fang, "Simultaneous Determination of Dexamethasone, Ondansetron, Granisetron, Tropisetron, and Azasetron in Infusion Samples by HPLC with DAD Detection," Journal of Analytical Methods in Chemistry, vol. 2017, Article ID 6749087, 2017.

[39] Secretaria de Salud (SSA), Criterios para la validación de métodos Fisicoquímicos, [Online], Available: http://www.cofepris.gob.mx/TyS/Documents/TercerosAutorizados/cvfq032011 .pdf, 2011.

[40] S. B. Da Silva, A. Oliveira, D. Ferreira, B. Sarmento, and M. Pintado, "Development and validation method for simultaneous quantification of phenolic compounds in natural extracts and nanosystems," Phytochemical Analysis, vol. 24, no. 6, pp. 638644, 2013

[41] L. Ying, W. Si-Wang, T. Hong-Hai, and C. Wei, "Simultaneous quantification of six main active constituents in Chinese Angelica by high-performance liquid chromatography with photodiode array detector," Pharmacognosy Magazine, vol. 9, no. 34, pp. 114-119, 2013.

[42] D. B. Shenoy and M. M. Amiji, "Poly(ethylene oxide)-modified poly( $\varepsilon$-caprolactone) nanoparticles for targeted delivery of tamoxifen in breast cancer," International Journal of Pharmaceutics, vol. 293, no. 1-2, pp. 261-270, 2005.

[43] A. Dalpiaz, F. Sacchetti, A. Baldisserotto et al., "Application of the "in-oil nanoprecipitation" method in the encapsulation of hydrophilic drugs in PLGA nanoparticles," Journal of Drug Delivery Science and Technology, vol. 32, pp. 283-290, 2016. 

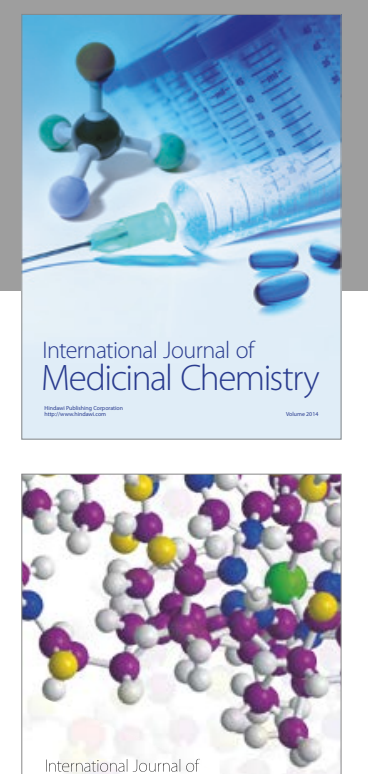

Carbohydrate Chemistry

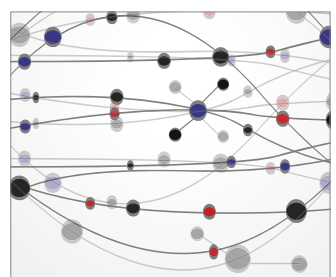

The Scientific World Journal
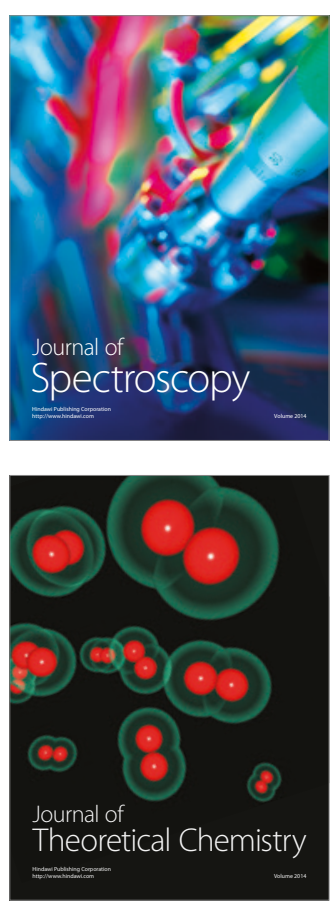
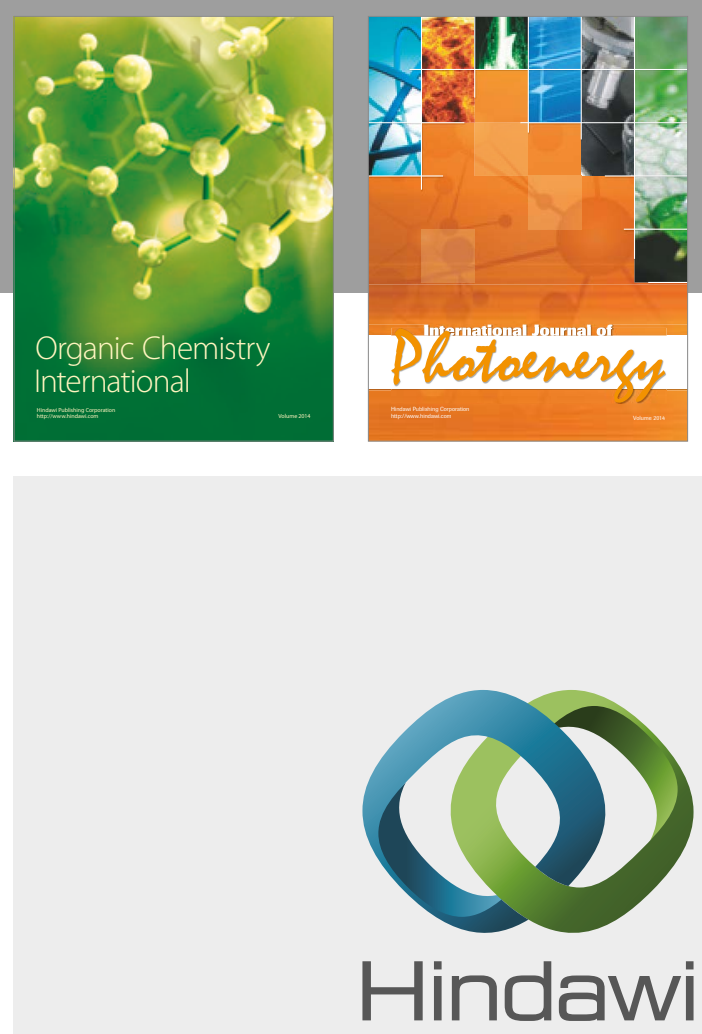

Submit your manuscripts at

https://www.hindawi.com

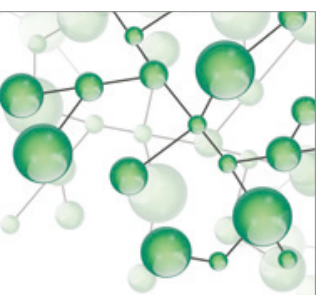

International Journal of

Inorganic Chemistry

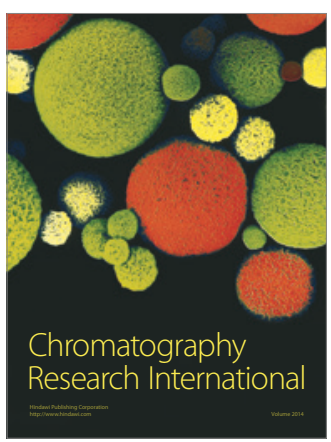

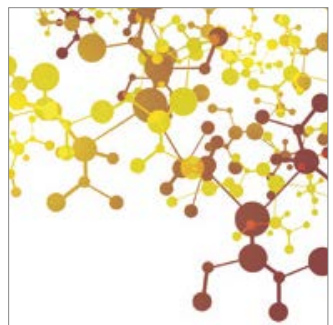

Applied Chemistry
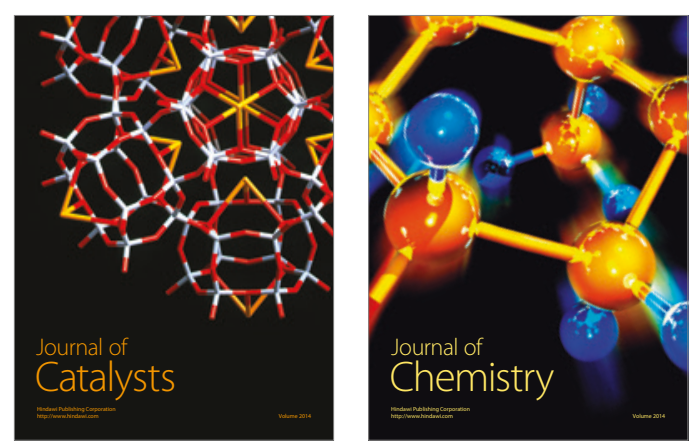
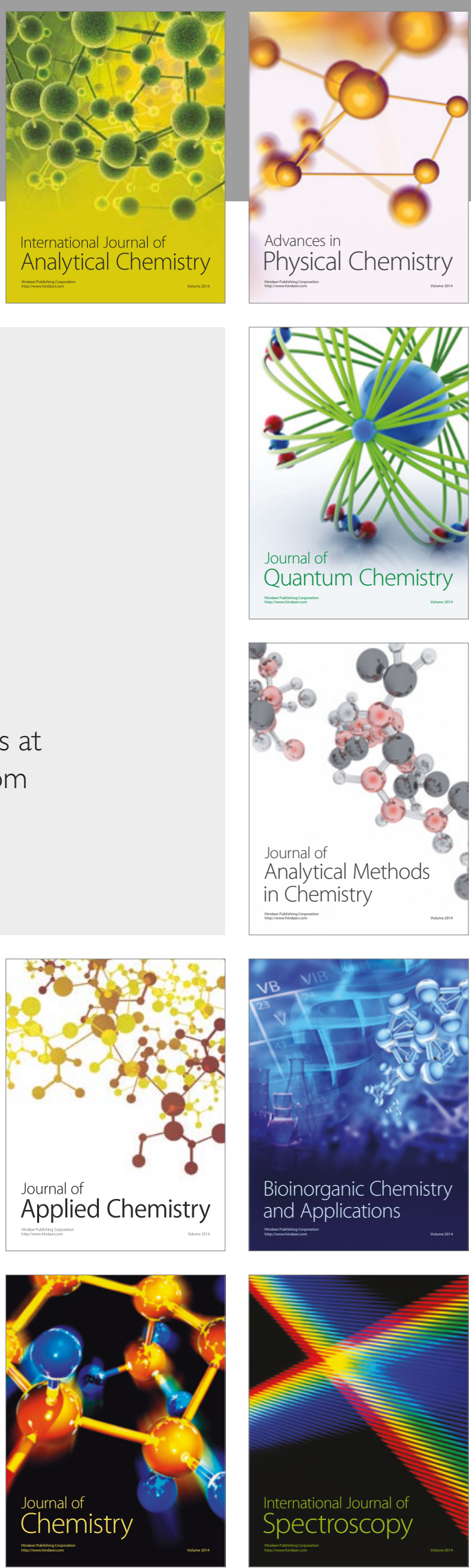